\title{
EVOLUTION AND BIOLOGY.
}

From the Greeks to Darwin. H. F. OsBonn. Columbia University Biological Series, No. I. New York and London. Macmillan, 1894. Pp. $\mathrm{X}+259$.

Amphioxas and the Ancestry of the Vertebrates. A. Willey. Columbia University Biological Series, No. 2. New York and London. Macmillan, 1894. Pp. XIV +316.

In these two volumes we have the beginning of a biological series which promises to be of importance for psychologists, since the topics of these and other volumes announced are the broader and more philosophical ones in the settlement of which the theory of the mental life is also involved. Prof. Osborn traces the history of the evolution idea before Darwin in an interesting way and with great perspicuity of style. From the psychologist's point of view more reference to mental development might possibly have been made; and yet it may be that the author found that his intimations of Darwinism before Darwin were not capable of such a reference. The book of Dr. Willey deals with the very vital question of the ancestry of the vertebrates; and while the conclusions upon the broader matters of descent are not large, still psychologists should know many more facts than they do of just the sifted kind which are here given. Our space only allows us to recommend these books, not on our own authority indeed, but as already approved by the biological authorities to whom we must defer.

\section{The Factors in Organic Evolution. D. S. JoRDan. Boston, Ginn \& Co., I894. Pp. V+149.}

It is difficult to see what purpose this volume can serve. Dr. Jordan prints a great mass of catch-sentences, clauses, and words under the main headings of current evolution thought, sometimes calling upon his colleagues to treat special topics in the same brief and unsuggestive way. It is possible, of course, that the author may find such a 'syllabus' useful in the hands of his classes, while he himself fills out the outline by lecturing. But why he should publish it-why? Those readers who know what the terms and catchwords mean, and know intelligently, do not need to be reminded of the categories of the subject; and those who do not, are not taught. Possibly a few teachers who lack time to plan their own lectures may follow the author's skeleton. The peculiar way of printing the book with double blank pages throughout would seem to indicate that this is the writer's idea. But time-limits and sense-limits in different schools and colleges are so different that independent men will probably prefer to do their own schematization. 